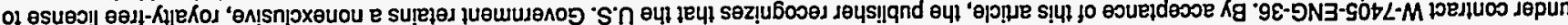

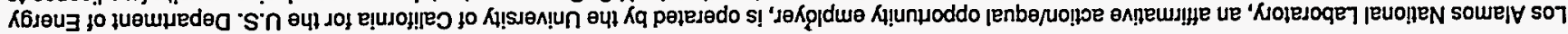

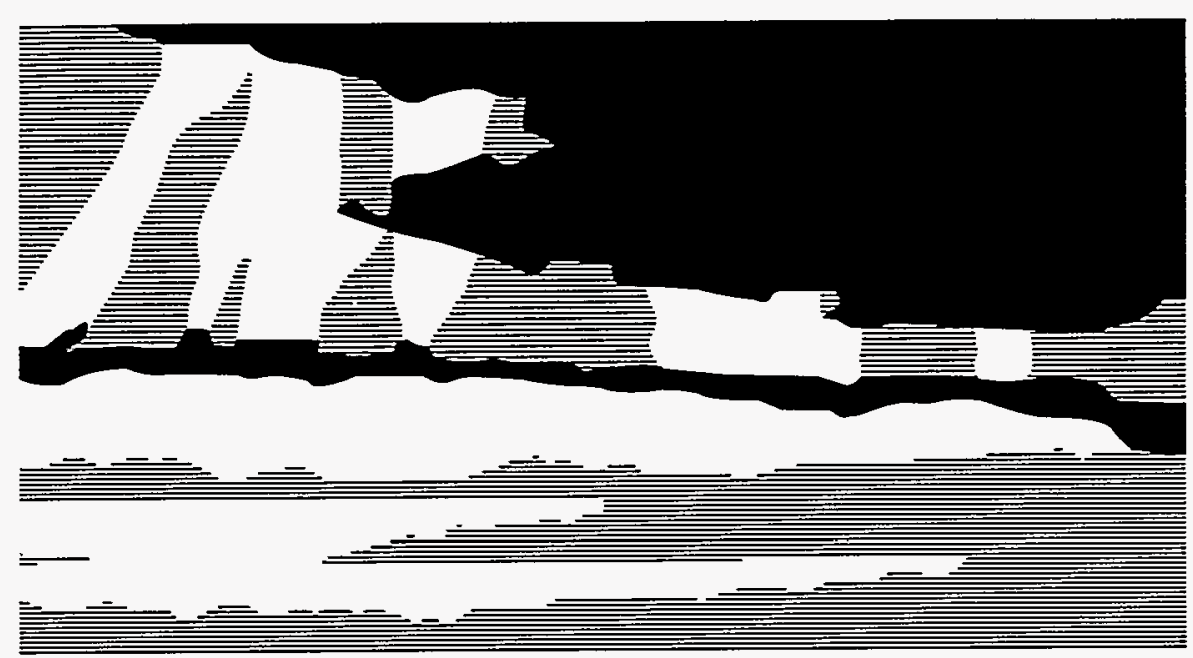




\section{DISCLAIMER}

Portions of this document may be illegible in electronic image products. Images are produced from the best available original document. 


\section{DISCLAIMER}

This report was prepared as an account of work sponsored by an agency of the United States Government. Neither the United States Government nor any agency thereof, nor any of their employees, makes any warranty, express or implied, or assumes any legal liability or responsibility for the accuracy, completeness, or usefulness of any information, apparatus, product, or process disclosed, or represents that its use would not infringe privately owned rights. Reference herein to any specific commercial product, process, or service by trade name, trademark, manufacturer, or otherwise does not necessarily constitute or imply its endorsement, recommendation, or favoring by the United States Government or any agency thereof. The views and opinions of authors expressed herein do not necessarily state or reflect those of the United States Government or any agency thereof. 


\title{
REGIONAL LOCATION IN WESTERN CHINA
}

\author{
Allen H. Cogbill \& Lee K. Steck \\ Earth \& Environmental Sciences Division \\ Los Alamos National Laboratory \\ Los Alamos, NM 87545
}

Sponsored by DOE

\begin{abstract}
Accurately locating seismic events in western China using only regional seismic stations is a challenge. Not only is the number of seismic stations available for locating events small, but most stations available to researchers are often over $10^{\circ}$ distant. Here we describe the relocation, using regional stations, of both nuclear and earthquake sources near the Lop Nor test site in western China. For such relocations, we used the Earthquake Data Reports provided by the U. S. Geological Survey (USGS) for the reported travel times. Such reports provide a listing of all phases reported to the USGS from stations throughout the world, including many stations in the People's Republic of China. LocSAT was used as the location code. We systematically relocated each event in this study several times, using fewer and fewer stations at each relocation, with the farther stations being eliminated at each step. We found that location accuracy, judged by comparing solutions from few stations to the solution provided using all available stations, remained good typically until fewer than seven stations remained. With a good station distribution, location accuracy remained surprisingly good (within $7 \mathrm{~km}$ ) using as few as 3 stations. Because these relocations were computed without good station corrections and without sourcespecific station corrections (that is, path corrections), we believe that such regional locations can be substantially improved, largely using static station corrections and source-specific station corrections, at least in the Lop Nor area, where sources have known locations. Elsewhere in China, we must rely upon known locations of regionally-recorded explosions. Locating such sources is clearly one of the major problem to be overcome before we can provide event locations with any assurance from regional stations. Inasmuch as small events may only be detected at regional stations, it is paramount to find such sources, as they represent "ground truth".
\end{abstract}

Key words: seismic, location, regional 


\section{INTRODUCTION}

Historically, perhaps the most basic criterion used to discriminate between earthquakes and nuclear explosions was simply the location of an event, for those powers that did test nuclear weapons did so at well-established test sites. For example, the People's Republic of China (PRC) has historically conducted weapons testing at the Lop Nor nuclear test site. As a result, teleseismic discrimination has focused on test sites: events initially located away from the nuclear test sites were largely ignored. Under a CTBT, however, event location may become more important, for an explosive event located away from both traditional testing areas and away from known mines is suspicious. Indeed, an explosive event located "close" to a mining area could be problematical, depending upon the uncertainty of the estimated location and its proximity to the mine. Reliable estimates of location uncertainty become extremely important under a CTBT.

We report here initial results on a study of the capability to locate seismic events in China, particularly western China, using only regional data. At present, no seismic arrays are available to us to assist in the location of regional events in western China. Thus, we are constrained to use only travel time data from single stations. Our first objective is to estimate the reliability of location methods utilizing only travel times recorded at regional seismic stations.

In order to assess the reliability of our location methods, accurate locations of the seismic sources located must be independently available. For China, this presents an immediate problem, as the only set of accurately-known source locations is the set of nuclear events detonated at the Chinese test site at Lop Nor. We can therefore characterize the capability to locate events from the Lop Nor region, but nowhere else in China. It is possible to utilize well-recorded, large earthquakes having shallow foci as "known" sources, but uncertainties in the positions of such events will always render the location characterization of such areas less certain. This type of inherent uncertainty afflicts any attempt at estimating the location capability of a particular method, such as one utilizing waveform analysis rather than travel-time analysis. Independent studies are ongoing to locate the positions of other types of seismic sources in China, notably mining blasts. The success of the location characterization studies is strongly dependent upon the success of these parallel studies of seismic source location.

\section{RESEARCH ACCOMPLISHED}

In the initial stage of this work, we have chosen to test the LocSAT hypocenter location algorithm (Bratt \& Bache, 1988) by locating 7 known nuclear explosions at the Lop Nor test site. Observed travel times were taken from the United States Geological Survey's Earthquake Data Reports (EDR). The EDR data are sorted by epicentral distance (from near to far), thus permitting us to easily test the effects of station number and proximity on epicenter location. In the results which follow, we used only the first arrivals, usually indicated in the EDRs as P, with an occasional Pn and some PKP.

Travel times are determined from the AK135 tables, corrected for ellipticity, with no bulk static or source-specific station corrections (SSSC's). Beginning with picks from the nearest 300 stations, we gradually eliminated more distant stations, until only the 3 closest stations remain. Note that we are determining epicenter only, holding depth fixed at 0 . We used the closest station as the starting location of the inversion. Table 1 lists the explosions we have re-located, and Table 2 provides a sample run for one of them. The distribution of regional stations used for relocating the nuclear events is shown in Figure 1, along with the locations of Lop Nor and the former Soviet nuclear test site near Semipalatinsk.

In general, LocSAT epicenters are in good agreement with the EDR locations, which in some cases use upwards of 600 picks. Some systematic differences are to be expected, as the 


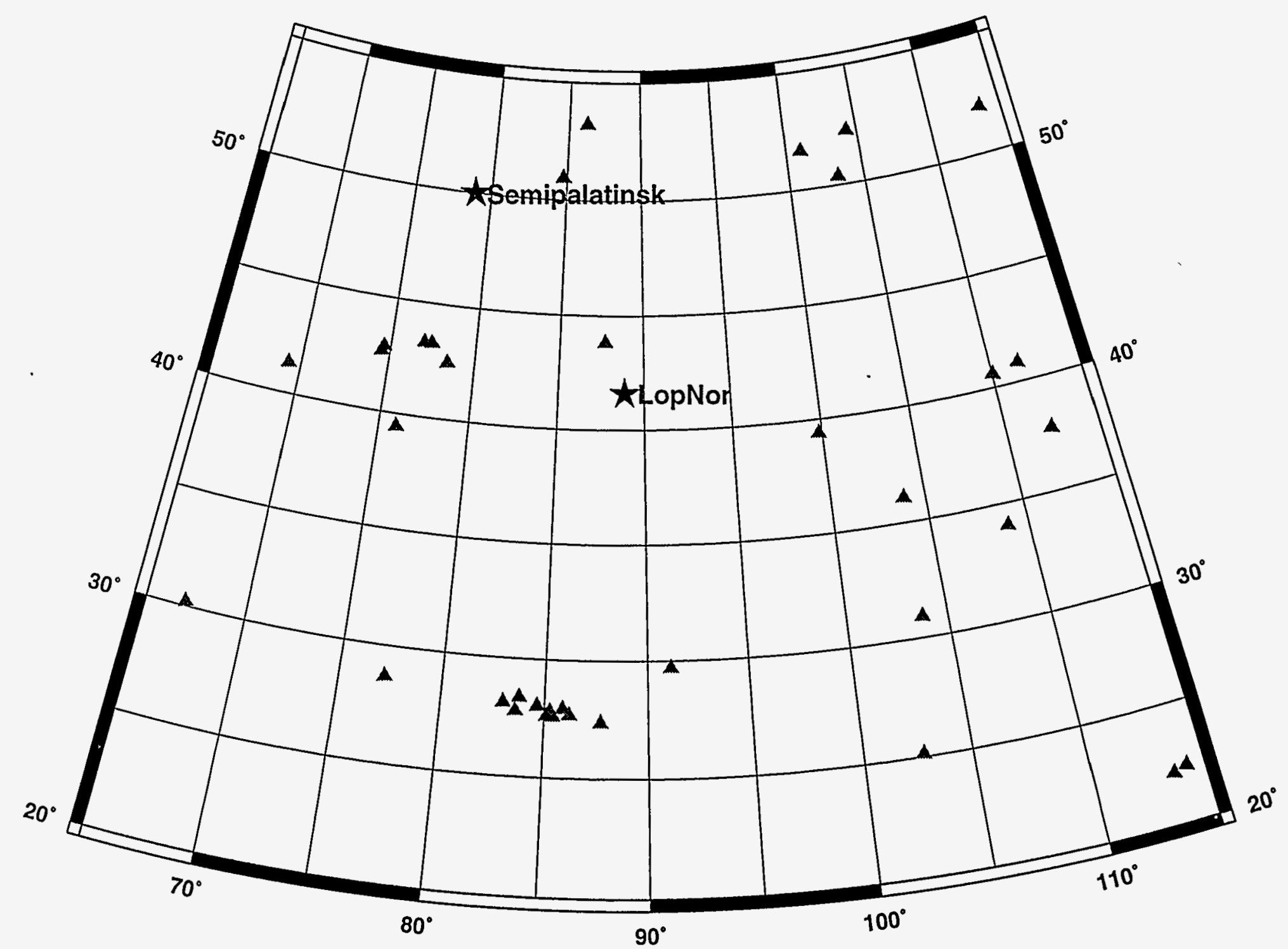

Figure 1. Distribution of EDR stations (triangles) used for relocating nuclear events in this study. 
EDR locations use the J-B travel time tables for its locations, rather than AK135. For runs using more than 75 picks, location differences between the LocSAT results and the EDR results were typically less than $5 \mathrm{~km}$ in both latitude and longitude. The inversion is typically stable down to 5 stations, at which point average lat/lon errors are still less than $10 \mathrm{~km}$. For 3 and 4 stations, the azimuthal distribution of stations sometimes became unfavorable, resulting in LocSAT solutions diverging dramatically from the EDR locations. This occurred in 3 of the 7 relocations. For the other 4 blasts, LocSAT still performed well, with latitude errors generally less than $22 \mathrm{~km}$ and longitude errors less than $10 \mathrm{~km}$. We have also compared the LocSAT epicenters with the those of Gupta (1995), which were derived from a master event relocation based on accurate satellite Iocations of the June 27, 1973 and October 3, 1984 Lop Nor nuclear tests. Results were very similar to those of the EDR relocations.

Table 1. Nuclear events relocated in this study.

$\begin{array}{cccccccc}\text { Date } & \text { Origin Time Latitude } & \text { Long. } & \text { Depth } & \mathrm{m}_{\mathrm{b}} & \text { Ms } \\ 90 / 05 / 26 & 07: 59: 57.8 & 41.566 & 88.688 & 0 & 5.4 & \\ 90 / 08 / 16 & 04: 59: 57.6 & 41.564 & 88.770 & 0 & 6.2 & \\ 92 / 05 / 21 & 04: 59: 57.5 & 41.604 & 88.813 & 0 & 6.5 & 5.0 \\ 92 / 09 / 25 & 07: 59: 59.9 & 41.763 & 88.387 & 0 & 5.0 & \\ 93 / 10 / 05 & 01: 59: 56.6 & 41.667 & 88.695 & 0 & 5.9 & 4.7 \\ 94 / 06 / 10 & 06: 25: 57.8 & 41.527 & 88.710 & 0 & 5.8 & \\ 94 / 10 / 07 & 03: 25: 57.8 & 41.574 & 88.680 & 0 & 5.9 & \\ 95 / 08 / 17 & 00: 59: 57.0 & 41.570 & 88.730 & 0 & 6.1 & \end{array}$

The relocation of the June 1994 event is enlightening. The details of its relocation are shown as Table 2; Figure 2 shows the spatial distribution of the 10 stations nearest the event. Note that, with the exception of WMQ, located only $2.4^{\circ} \mathrm{NNW}$ of Lop Nor, regional stations are not located very close to the test site: the next closest station providing data for this study is nearly $9^{\circ}$ distant from Lop Nor. One of the implications of this observation is that, for locating events in the Lop Nor region, the details of the travel-time curves from $0-9^{\circ}$ may be irrelevant, as no observations in this interval are likely to be available for locating events. In fact, the closest station to Lop Nor available for the June 1994 relocation is FRU, over $10^{\circ}$ distant from the event. Figure 2 reveals a relatively good station distribution, despite the fact that 8 reporting stations are grouped very close to one another. Figure 3 shows how the location of the event varies as more stations are eliminated. Even using only 3 stations, the mislocation is only $\sim 7 \mathrm{~km}$. Some of the other nuclear events relocated had very poor station distributions, and consequently their mislocations were greater. Parenthetically, we note that the distribution of reporting stations was quite different from event to event, which is somewhat surprising in view of the fact that all these events were large enough to be well-recorded. We also note that travel times were often reported by PRC-controlled stations, although reporting times from these station commonly showed high residuals, leading us to suspect these times. Note that times from WMQ, the closest station to the events, were never available.

As a first estimate of bulk static corrections, we averaged the EDR station residuals over all events in a large region $\left(10^{\circ}-60^{\circ}\right.$ latitude, $50^{\circ}-120^{\circ}$ longitude) around Lop Nor, and incorporated them into the LocSAT algorithm. Any improvement in epicenter location was very small. However, this set of events contained many regional arrivals having relatively large incident angles (from the vertical). A better approach would be to use residuals for events at distances greater than $40^{\circ}$, arriving with much smaller incident angles. These would more accurately model bulk static station corrections. We have estimated these corrections, but have not yet incorporated them into our results.

In addition to relocating several Lop Nor nuclear explosions, we also relocated an $m_{b}=6.2$ earthquake that occurred near the Lop Nor test site, as well as several of its aftershocks, ranging 


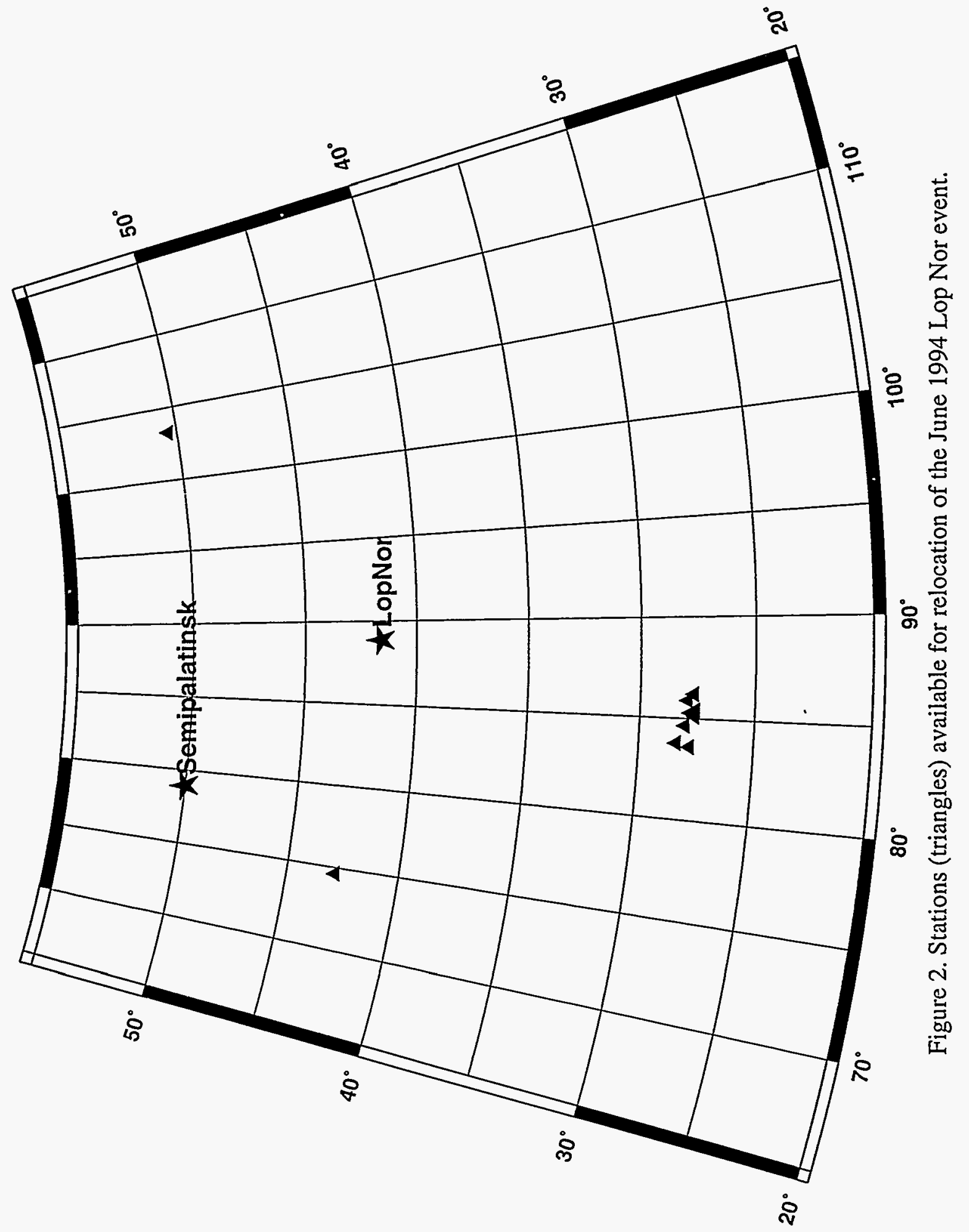




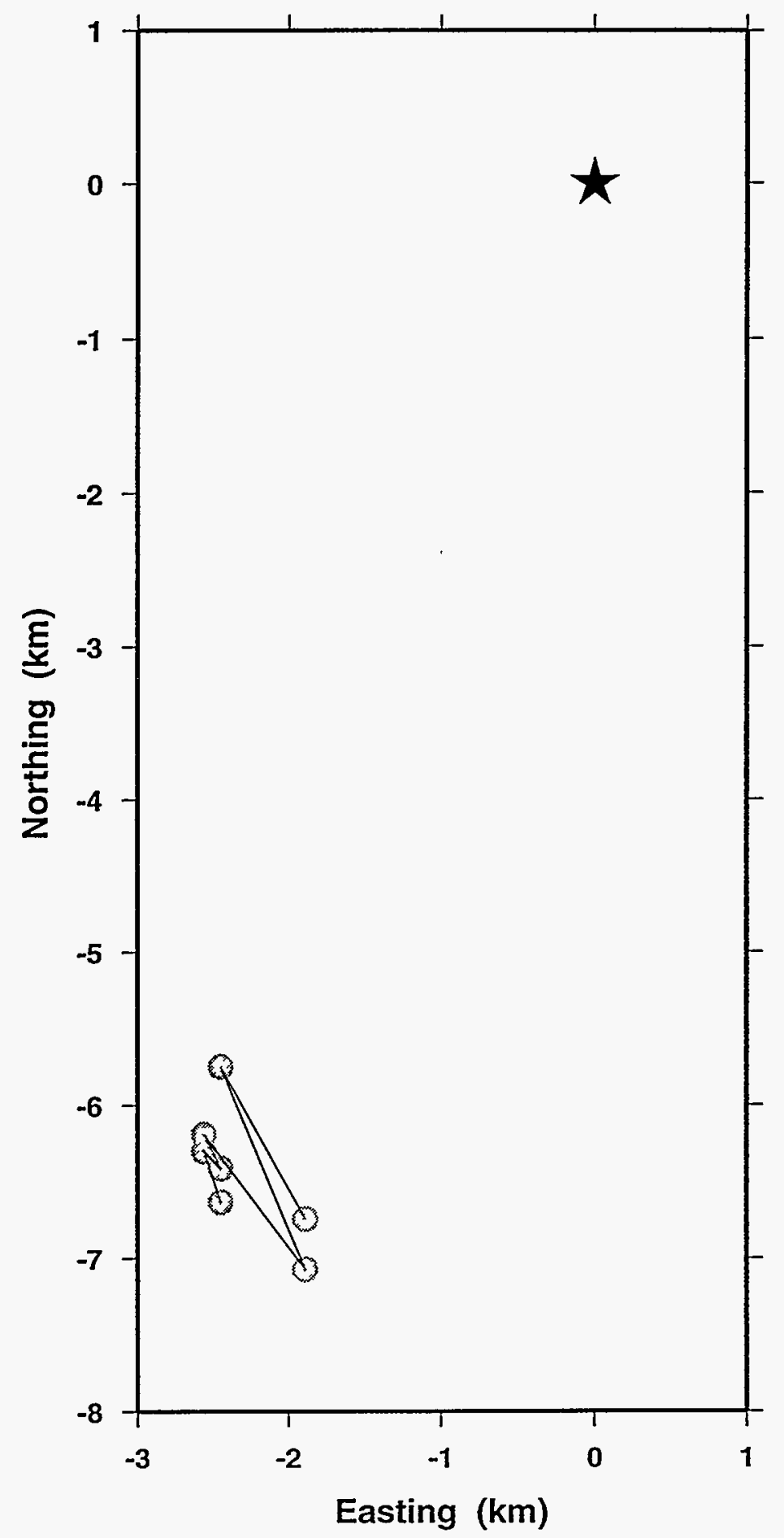

Figure 3. Relocations of June 1994 Lop Nor event. Star is the EDR location, circles are positions of our relocated events. Only 10 nearest stations used. Locations shown use $10,9, \ldots, 4$ stations in solutions. 
in magnitude from 5.8 to 3.8. We followed the same procedure as for the explosions, except that we now allowed depth to vary, and as a result the number of stations could only be reduced to 4 . In all cases, LocSAT worked well, finding epicenters to within $10 \mathrm{~km}$ in latitude and longitude of the EDR epicenters with as few as 6 stations. However, with depth varying, origin times were off by several seconds, and depths by up to $60 \mathrm{~km}$. Using only 4 or 5 stations, latitude and longitude errors were less than $25 \mathrm{~km}$, with one exception, though depth errors in some cases reached over $100 \mathrm{~km}$ and origin time errors approached 8 seconds. In several instances, the inversion using only 4 stations failed. Table 3 lists the earthquakes used and tabulates results from 3 of the 7 earthquakes studied. In general, for both earthquakes and explosions, the error ellipses surrounding the LocSAT location encompassed the reference location, but were not grossly large.

Table 2. Results for the June 1994 Chinese nuclear test. Latitude, longitude, and origin time (ot) errors are the difference between the EDR and LocSAT locations. Other errors shown are estimated by LocSAT (confidence error ellipse and origin time). The confidence level was set to 0.90. Below, the first column shows the number of stations used, and the second shows the maximum azimuthal gap. The sixth, seventh and eighth columns give the ratio of semi-major and semi-rninor axes of the error ellipse, the value of the semi-minor axis, and the strike of the error ellipse.

\begin{tabular}{|c|c|c|c|c|c|c|c|c|}
\hline \multirow{2}{*}{\multicolumn{2}{|c|}{$\begin{array}{c}\left({ }^{\circ}\right) \\
\text { nsta az gap }\end{array}$}} & $\left(^{\circ}\right)$ & $\left(^{\circ}\right)$ & $(\mathrm{sec})$ & \multicolumn{2}{|r|}{$(\mathrm{km})$} & \multicolumn{2}{|c|}{$\left({ }^{\circ}\right) \quad(\mathrm{sec})$} \\
\hline & & & lon err & ot err & $\mathrm{naj} / \mathrm{m}$ & . & & \\
\hline 300 & 49.0 & 0.005 & -0.040 & -1.872 & 1.27 & 5.5 & 22.8 & 0.300 \\
\hline 150 & 49.0 & 0.026 & & & & & 24.2 & \\
\hline & 65.0 & 0.028 & & & & & 170.2 & \\
\hline$\pi$ & 65.0 & 0.058 & & & & & & \\
\hline 40 & 76.0 & 0. & & & & & & \\
\hline & 76.0 & & & & & & & \\
\hline & & & & & & & & \\
\hline 10 & & & & & & & & \\
\hline & & & & & & & & \\
\hline & & & & & & & & \\
\hline & & & & & & & & \\
\hline & & & & & & & & \\
\hline & & & & & & & & \\
\hline & & & & & & 22.1 & & \\
\hline & & & 0.017 & & 1.55 & 24.5 & $133: 9$ & \\
\hline
\end{tabular}

Table 3. List of 7 earthquakes relocated during this study.

\begin{tabular}{lccccccc} 
\# & Date Origin Time & Latitude & Long. & Depth & $\mathrm{mb}$ & $\mathrm{Ms}$ \\
\hline 1 & $93 / 10 / 02$ & $08: 42: 32.7$ & 38.190 & 88.663 & 14 & 6.2 & 6.3 \\
2 & $93 / 10 / 02$ & $09: 20: 12.3$ & 38.206 & 89.284 & 10 & 4.9 & \\
3 & $93 / 10 / 02$ & $09: 43: 19.5$ & 38.169 & 88.605 & 14 & 5.8 & 5.3 \\
4 & $93 / 10 / 02$ & $17: 23: 33.3$ & 38.171 & 88.690 & 14 & 5.6 & 5.0 \\
5 & $93 / 10 / 02$ & $19: 16: 43.0$ & 38.079 & 88.831 & 10 & 3.8 & \\
6 & $93 / 10 / 02$ & $23: 49: 59.7$ & 38.359 & 88.878 & 10 & 4.8 & \\
7 & $93 / 10 / 07$ & $03: 26: 58.9$ & 38.214 & 88.726 & 11.39 & 5.0 & \\
1Depth fixed using depth phase. & & & &
\end{tabular}


Table 4. Results are for 3 earthquakes (numbers 1, 7, and 5) from the above sequence, which occurred close to Lop Nor. Latitude, longitude, origin-time (ot), and depth errors are the difference between the EDR and LocSAT locations. Other errors shown are estimated by LocSAT (confidence error ellipse and origin time). The confidence level was set at 0.90 . Below, the first column shows the number of stations used, and the second shows the maximum azimuthal gap. The seventh, eighth and ninth columns give the ratio of semi-major and semi-minor axes of the error ellipse, the value of the semi-minor axis, and the strike of the error ellipse.

Earthquake $1(\mathrm{Mb}=6.2)$

$\left(l^{\circ}\right) \quad\left({ }^{\circ}\right) \quad\left({ }^{\circ}\right) \quad(\mathrm{sec}) \quad(\mathrm{km}) \quad(\mathrm{km}) \quad\left(^{\circ}\right) \quad(\mathrm{sec})$

\begin{tabular}{crrrrrrrrr} 
nsta & az gap lat err lon err & \multicolumn{2}{c}{ ot err deperr } & \multicolumn{3}{c}{ maj/min minor strike time err } \\
\hline 300 & 36.0 & -0.023 & -0.035 & -1.372 & 3.5 & 1.75 & 4.8 & 11.1 & 3.700 \\
150 & 36.0 & -0.009 & -0.037 & -0.355 & 11.0 & 1.71 & 5.2 & 8.8 & 4.200 \\
75 & 36.0 & 0.007 & -0.037 & -0.374 & 11.0 & 1.37 & 7.3 & 5.5 & 4.800 \\
50 & 36.0 & -0.003 & -0.052 & -1.269 & 4.0 & 1.17 & 9.2 & 168.4 & 5.300 \\
40 & 45.0 & -0.004 & -0.062 & -0.483 & 10.3 & 1.16 & 9.8 & 171.1 & 6.400 \\
30 & 48.0 & -0.010 & -0.075 & -0.345 & 11.3 & 1.19 & 10.1 & 1.6 & 7.800 \\
20 & 52.0 & -0.032 & -0.041 & -4.159 & -30.2 & 1.02 & 13.2 & 64.0 & 1.000 \\
10 & 99.0 & -0.045 & -0.069 & -4.905 & -116. & 1.33 & 15.3 & 31.8 & 2.000 \\
9 & 115.0 & -0.049 & -0.079 & -4.933 & -121. & 1.83 & 16.6 & 55.4 & 2.100 \\
8 & 115.0 & -0.048 & -0.079 & -4.924 & -120. & 1.76 & 18.1 & 49.4 & 2.200 \\
7 & 115.0 & -0.004 & -0.060 & -1.577 & 5.6 & 1.11 & 20.2 & 83.9 & 333.9 \\
6 & 115.0 & -0.010 & -0.061 & -0.575 & 14.1 & 1.17 & 19.3 & 84.5 & 1.400 \\
5 & 115.0 & -0.020 & -0.062 & -0.647 & 14.1 & 1.09 & 22.2 & 21.3 & 1.600 \\
$4 \pi$ & 115.0 & -5.640 & 0.973 & -0.647 & 14.1 & 1.09 & 22.2 & 21.3 & 1.600
\end{tabular}

10 stations nearest to Earthquake 1

\begin{tabular}{|c|c|c|c|c|}
\hline & $\left(^{\circ}\right)$ & $\left(^{\circ}\right)$ & $(\mathrm{km})$ & $\left(^{\circ}\right)$ \\
\hline Station & Latitude & Longitude & Elev & Distance \\
\hline WMQ & 43.8211 & 87.6950 & 0.970 & 5.6731 \\
\hline GTA & 39.4106 & 99.8144 & 1.341 & 8.7925 \\
\hline TLG & 43.2667 & 77.3833 & 0.850 & 9.9472 \\
\hline $\mathrm{KSH}$ & 39.4553 & 75.9800 & 1.286 & 9.9789 \\
\hline GUN & 27.9106 & 85.8792 & 2.900 & 10.5132 \\
\hline KKN & 27.7900 & 85.2800 & 1.920 & 10.7520 \\
\hline DMN & 27.6089 & 85.1058 & 2.225 & 10.9656 \\
\hline FRU & 42.8333 & 74.6167 & 0.655 & 11.6515 \\
\hline $\mathrm{AAK}$ & 42.6389 & 74.4939 & 1.645 & 11.6768 \\
\hline $\mathrm{LZH}$ & 36.0867 & 103.8444 & 1.560 & 12.2975 \\
\hline
\end{tabular}


Table 4 (continued).

Earthquake $7(\mathrm{Mb}=5.0)$

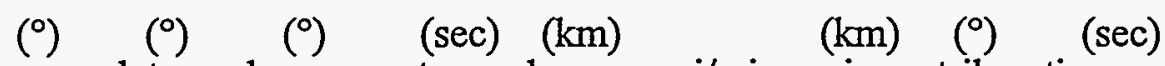

nsta az gap lat_err lon_err ot_err deperr maj/min minor strike time_err

$\begin{array}{llllllllll}75 & \overline{74.0} & -0.029 & -0.071 & -5.206 & -23.1 & 1.55 & 9.5 & 19.4 & 2.400\end{array}$

$\begin{array}{llllllllll}50 & 74.0 & -0.033 & -0.079 & -5.178 & -22.4 & 1.55 & 9.7 & 21.7 & 2.600\end{array}$

$\begin{array}{llllllllll}40 & 74.0 & -0.033 & -0.080 & -5.180 & -22.4 & 1.52 & 9.9 & 22.2 & 2.600\end{array}$

$\begin{array}{llllllllll}30 & 74.0 & -0.033 & -0.098 & -4.084 & -11.6 & 1.41 & 10.7 & 24.5 & 6.300\end{array}$

$\begin{array}{llllllllll}20 & 74.0 & -0.040 & -0.103 & -5.067 & -20.6 & 1.24 & 12.7 & 14.7 & 3.900\end{array}$

$\begin{array}{llllllllll}10 & 113.0 & -0.062 & -0.174 & -2.556 & 2.7 & 1.25 & 17.7 & 54.6 & 36.000\end{array}$

$\begin{array}{llllllllll}9 & 113.0 & -0.058 & -0.151 & -1.593 & 11.3 & 1.20 & 16.4 & 26.6 & 1.200\end{array}$

$\begin{array}{llllllllll}8 & 129.0 & -0.094 & -0.140 & -5.688 & -38.8 & 1.14 & 19.1 & 48.7 & 2.000\end{array}$

$\begin{array}{llllllllll}7 & 113.0 & -0.059 & -0.125 & -5.804 & -59.2 & 1.18 & 20.0 & 25.7 & 1.900\end{array}$

$\begin{array}{llllllllll}6 & 245.0 & -0.059 & -0.127 & -5.821 & -61.7 & 1.14 & 20.4 & 25.0 & 1.900\end{array}$

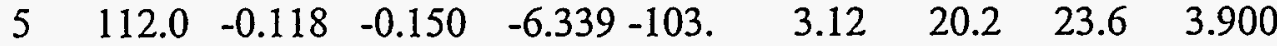

$\begin{array}{llllllllll}4 \pi & 112.0 & -5.616 & 1.036 & -6.339 & 11.3 & 3.12 & 20.2 & 23.6 & 3.900\end{array}$

¿Convergence error

10 stations nearest to Earthquake 7

$\begin{array}{lcrrc} & \left({ }^{\circ}\right) & \left({ }^{\circ}\right) & (\mathrm{km}) & \left({ }^{\circ}\right) \\ \text { Station } & \text { Latitude } & \text { Longitude } & \text { Elev } & \text { Distance } \\ \text { WMQ } & 43.8211 & 87.6950 & 0.970 & 5.6558 \\ \text { GTA } & 39.4106 & 99.8144 & 1.341 & 8.7391 \\ \text { KSH } & 39.4553 & 75.9800 & 1.286 & 10.0230 \\ \text { FRU } & 42.8333 & 74.6167 & 0.655 & 11.6843 \\ \text { SHL } & 25.5667 & 91.8833 & 1.600 & 12.8905 \\ \text { ZAK } & 50.3833 & 103.2833 & 0.000 & 15.9820 \\ \text { BTO } & 40.5983 & 110.0183 & 1.120 & 16.6256 \\ \text { KMI } & 25.1233 & 102.7400 & 1.945 & 17.6522 \\ \text { IRK } & 52.2717 & 104.3100 & 0.467 & 17.7763 \\ \text { HHC } & 40.8494 & 111.5636 & 1.169 & 17.8050\end{array}$

Earthquake $5(\mathrm{Mb}=3.8)$

$\left({ }^{\circ}\right) \quad\left({ }^{\circ}\right) \quad\left({ }^{\circ}\right) \quad(\mathrm{sec}) \quad(\mathrm{km}) \quad(\mathrm{km}) \quad\left(^{\circ}\right) \quad(\mathrm{sec})$

nsta az_gap lat_err lon_err ot_err deperr maj/min minor strike time_err

$\begin{array}{llllllllll}7 & 184.0 & -0.044 & -0.035 & -5.401 & -24.2 & 2.67 & 17.1 & 16.7 & 4.300\end{array}$

$\begin{array}{llllllllll}6 & 256.0 & -0.033 & -0.049 & -2.609 & 1.9 & 2.32 & 19.7 & 15.7 & 23.300\end{array}$

$\begin{array}{llllllllll}5^{\mathrm{m}} & 187.0 & -0.017 & -0.050 & 3.188 & 10.0 & 2.40 & 19.0 & 16.5 & 2.100\end{array}$

$\begin{array}{llllllllll}41 & 187.0 & -5.751 & 1.141 & 3.188 & 10.0 & 2.40 & 19.0 & 16.5 & 2.100\end{array}$

$\mathrm{m}$ Convergence not attained (maximum iterations reached)

$\checkmark$ Convergence error 
Table 4 (continued)

10 stations nearest to Earthquake 5

\begin{tabular}{lcrrr} 
& $\left({ }^{\circ}\right)$ & \multicolumn{1}{c}{$\left({ }^{\circ}\right)$} & $(\mathrm{km})$ & \multicolumn{1}{c}{$\left({ }^{\circ}\right)$} \\
Station & Latitude & Longitude & Elev & Distance \\
WMQ & 43.8211 & 87.6950 & 0.970 & 5.8006 \\
GTA & 39.4106 & 99.8144 & 1.341 & 8.6855 \\
KSH & 39.4553 & 75.9800 & 1.286 & 10.1308 \\
LZH & 36.0867 & 103.8444 & 1.560 & 12.1559 \\
XAN & 34.0394 & 108.9214 & 0.630 & 16.7340 \\
TIY & 37.7131 & 112.4342 & 0.850 & 18.6263 \\
NB2 & 61.0397 & 11.2147 & 0.717 & 51.7633
\end{tabular}

\section{CONCLUSIONS AND RECOMMENDATIONS}

It is clear from this initial study that well-recorded events (i.e., high $\mathrm{S} / \mathrm{N}$ for times, good station distribution)in the Iop Nor region can be located rather accurately using only first arrival times at regional distances, even when only a small number of stations are available. Clearly the station distribution is one of the most important parameters controlling the reliability of a location. This result is well-known from a theoretical basis, of course. Also, it seems that, for single-station observations such as those used here, one does not need to be especially close to an event to provide a good estimate of its location. However, the events studied were wellrecorded; observed travel times from smaller events are likely to be less reliable, as well as less likely to have a good azimuthal distribution of recording stations, leading to greater error in their locations.

We plan to estimate both static station corrections and SSSCs for all stations of interest. These mostly include not only the stations used by the EDRs, but also digital stations near Lop Nor of interest to CTBT researchers. We hope to be able to attain a location uncertainty of less than $2 \mathrm{~km}$ using such methods. Constructing the SSSCs will require estimating local velocity structure at the stations of interest, at least along paths from Lop Nor to the station. Separately, we plan to estimate the effect of noisy first-arrival data with the use of Monte Carlo methods, thus simulating what might be times recorded from a small event in the Lop Nor region.

Finally, we re-emphasize that the characterization of location reliability for regions of the PRC away from Lop Nor is highly dependent upon independent measures of seismic sources' locations in such regions. We plan to work closely with those finding such locations in order to expand our studies to other portions of China. Calibration explosions at selected sites could be extremely beneficial, as well.

\section{REFERENCES CITED}

Bratt, Steven R. and Thomas C. Bache, 1988, Locating events with a sparse network of regional arrays, Bull. Seis. Soc. Am., 78(2), 780-798.

Gupta, Vipin, 1995, Locating nuclear explosions at the Chinese Test Site near Lop Nor, Science \& Global Security, 5, 205-244. 